\title{
VERSO AISLADO, VERSO SOLO, VERSO-POEMA
}

\author{
Por \\ ArCAdio Pardo
}

Y

A no se puede tratar de estos temas sin hacer referencia al imprescidible trabajo de Daniel Devoto publicado en los años 80 y $82^{1}$ en el que somete lo hasta entonces escrito sobre lo que es el verso a un riguroso examen. Pasa revista a las definiciones dadas anteriormente sobre las condiciones que requiere el verso para serlo, comprobando que la mayoría de los tratadistas consideran que para que una expresión pueda ser tenida como verso, esa expresión debe formar parte de una serie. Así lo afirman Díez Echarri, en su libro sobre el Siglo de Oro, ${ }^{2}$ aunque parece admitir la posibilidad de verso fuera de una serie con su matización de rara vez; Iuri Lotman, ${ }^{3}$ Benot ${ }^{4}$-que niega al verso la posibilidad de autonomía rítmica-, Balbín Lucas, ${ }^{5}$ María Josefa Canellada, ${ }^{6}$ Roman Jakobson ${ }^{7}$ - que deja abierta la posibilidad de que las estructuras rítmicas de un verso no se repitan en su serie-, Henríquez Ureña para quien cuando una frase tiene ritmo de verso es porque «se integra en el recuerdo

${ }^{1}$ Daniel DEVOTO, "Leves o aleves consideraciones sobre lo que es el verso", $C a$ hiers de Linguistique Hispanique Médiévale, 5, 1980/1982, 67-100; 7, 5-60.

${ }^{2}$ Emilio DÍEZ ECHARRI,: «el verso por sí sólo rara vez constituye unidad, porque no puede expresar un pensamiento, una volición, un sentimiento o un contenido psíquico de naturaleza creacional y de la clase que sea», Teorías métricas del Siglo de Oro, R.F.E., Anejo XLVII, Madrid, 1970, 172.

${ }^{3}$ Iuri LOTMAN, La structure du texte artistique, Paris, Gallimard, 1937. Citado por J. DOMÍNGUEZ CAPARRÓS in Métrica española, Madrid, Síntesis, 1993, 31.

${ }^{4}$ Citado igualmente por D. DEVOTO, op. cit., 80.

${ }^{5}$ Citado por Oldrich BELIC in En busca del verso español, Praha, Univerzita Karlova, 1976, 42.

${ }^{6}$ María Josefa CANELLADA, Diccionario de literatura española, Madrid, 1964

${ }^{7}$ Roman JAKOBSON, cit. por D. DEVOTO, op. cit., 78. 
de un patrón, e implica por tanto una serie»; ${ }^{8}$ Oldrich Belic. ${ }^{9}$ Y otros. La idea generalmente admitida es pues que el verso solo no existe, y cuando aparece es como recuerdo de un patrón preexistente.

Daniel Devoto admite en cambio que el verso existe «cuando se le restituye su estructura rítmica propia, independientemente de la serie o de la referencia a un patrón métrico». ${ }^{10} \mathrm{Y}$ admite que cada verso tiene su ritmo propio.

Por otra parte, la rima exige para existir que haya repetición. Sólo los versos blancos integrados en una serie son reconocidos como versos.

Daniel Devoto admite, pues, la posibilidad del verso autónomo y cree que se debe considerar verso al de Antonio Machado «Hoy es siempre todavía», que es sencillamente un octosílabo solo. Los tratadistas vienen a decir que ese tipo de frases responde a la estructura sintáctica más frecuente en la lengua, y siendo la estructura básica en español la frase octosilábica y sus adyacentes, puede ser que una expresión de este tipo suene a verso sin forzosamente tener que justificarlo como recuerdo de un patrón anterior. Por la misma razón se pueden dar ejemplos de expresiones aisladas con ritmo endecasílabo o alejandrino. Pues el hablante puede utilizar esos "versos" sin conciencia de que ha dicho un endecasílabo, o un alejandrino, por ejemplo. Cabe imaginar que se utilicen frases como ésta: «Tanto padecimiento para nada» / «Entró en casa a las cinco y se marchó a las siete».

Dos hechos pueden haber modificado las ideas anteriores: por una parte la irrupción en la poesía del versosibrismo; por otra parte, el abandono de la rima. El versolibrismo se libera del sistema de serie, de recurrencia rítmica, y del isosilabismo. Pensamos en el verso libre que no adopta un ritmo de cláusulas. Ninguno de los elementos del poema en verso libre permite que un verso, una línea de ese poema, obedezca a un concepto de serie.

\footnotetext{
${ }^{8}$ Citado in J. DOMÍNGUEZ CAPARRÓS, op. cit., 40-41.

${ }^{9}$ Oldrich BELIC, En busca del verso español, op. cit., 8.

${ }^{10}$ Citado por J. DOMÍNGUEZ CAPARRÓS, op. cit., 32.
} 
El abandono de la rima ha liberado al verso de las imposiciones de la estrofa. El verso ya no necesita "recordar" unas sonoridades anteriores y puede, por eso mismo, adquirir una independencia del conjunto en el que se encuentra.

Más que adoptar una posición en favor o en contra de la posibilidad del verso aislado o del verso solo, conviene indagar en la historia de la poesía, si han existido etapas, jalones que han podido favorecer la ida hacia una autonomía del verso aislado dentro de un poema largo, para llegar a la utiliación del verso solo o del verso-poema.

$1^{\circ}$ ) Los metricistas han señalado que, efectivamente, pueden considerarse "versos" muchos de los refranes tradicionales. Eleanor S. O'Kane nos ofrece múltiples ejemplos. ${ }^{11}$ Así los que siguen:

Amor non busca testigo. (p. 50)

¿Quién tornó del otro mundo? (p. 68)

y otros muy numerosos que pueden recogerse en los refraneros. Para Navarro Tomás este tipo de expresiones tienen valor de estrofa y utilizan generalmente el verso octosílabo; se trata en general de motes, lemas o proverbios. ${ }^{12}$ Parece un tanto difícil justificar el "valor de estrofa" de un refrán; aunque se podría admitir ese valor en refranes que presentan una rima interior: «E1 juego, poco e bueno» que en realidad son dos versos asonantados:

El juego,

poco e bueno.

Tampoco parece justo admitir con Balbín que sólo la estrofa tiene «plenitud idiomática completa». El verso de A. Machado que da Devoto como ejemplo («Hoy es siempre todavía») tiene,

${ }^{11}$ Eleanor S. O'KANE, Refranes y frases proverbiales españolas de la edad media, R.F.E., Anejo II, Madrçid, 1959.

12 NAVARRO TOMÁS, Arte del verso, Col. Málaga, México, [1968]. 
a su parecer, y también al nuestro, esa plenitud idiomática completa y es un verso octosílabo solo.

Lo mismo se dice de algunos títulos de obras literarias: Del rey abajo ninguno / Don Quijote de la Mancha / El convidado de piedra / El mágico prodigioso / El comendador de Ocaña / La feria de los discretos / A buen juez mejor testigo / Baladas de primavera, y muchos más.

Un primer salto será el de la utilización de refranes incorporados en series, entendiendo por serie la sucesión de versos que forman un mismo poema. Suelen aparecer como lema al que sigue el desarrollo de un ejemplo, o bien como conclusión del relato desarrollado, o también a modo de sentencia que viene a concentrar en pocas palabras lo antes expuesto o lo por exponer. Ejemplos de versos que sirven de introducción al poema o a la estrofa no escasean. Citamos algunos del Libro de Buen Amor:

«Siempre a la mala manera la sierra e altura» (estrofa 1006-1) «Alégrase el malo en dar por miel venino» (estrofa 1354-2);

o a modo de conclusión del poema o de parte de él:

«Quien tiene lo quel cumple, con ello sea pagado» (estrofa 206-1) «por malas vecindades se pierden heredades» (estrofa 260-4)

«Do non te quieren mucho non vayas a menudo» (estrofa 1320-4) «Amor, quien más te sigue, quémase cuerpo e alma» (estrofa 197-3). «AAy Muerte, muerta seas, muerta e malandante!» (estrofa 1520-1)

Si el poeta dispone en el cuerpo del poema -generalmente en posiciones inicial y final, como se ha visto- versos o expresiones que él tiene como tales, alguna razón profunda lo justificará para él.

Se inscriben en esta misma tradición los fabulistas, conservando la misma disposición de verso inicial que anuncia, o que sienta un precepto a ilustrar con un ejemplo, o bien recogiendo en un verso final, generalmente no separado, pero sin que esto sea de regla absoluta, como vamos a ver, en un verso final, aislado por puntuación, la consecuencia a modo de resultado de 
experiencia o también de consejo o moraleja. La Fontaine nos brinda numerosos ejemplos. ${ }^{13}$ Uno de esos versos iniciales reconoce utilizar un proverbio:

«Ne t'attends qu'à toi seul: c'est un commum proverbe»

(L'alouette et ses petits)

Otros, que son los más numerosos, introducen el tema:

«Un homme cherissoit éperdument sa chatte»

(La chatte métaphormosée en femme)

«L'avarice perd tout en voulant tout gagner»

(La poule aux œufs d'or)

«Un savetier chantoit du matin jusqu'au soir»

(La savetier et le financier).

«Ni l'or ni la grandeur ne nous rendent heureux»

(Philemon et Baucis)

«Rien ne sert de courir, il faut partir à temps»

(Le lièvre et la tortue)

De los versos finales citamos los siguientes:

«Car c'est double plaisir de tromper le trompeur.»

(Le coq et le renard, XV, lib. II)

«Où la Guêpe est passée, le Moucheron demeure.»

(Le Corbeau voulaint imiter l'Aigle)

«La vieillesse est impitoyable.»

(Le vieux Chat et la jeune Souris)

«Mieux vaut goujat debout qu'empereur enterré.»

(La matrone d'Ephèse)

${ }^{13}$ Las citas se hacen a partir de la edición LA FONTAINE, Fables, con una Vida de La Fontaine, introducción y notas por Edmon PILON y Fernand DAUPHIN, Paris, Classiques Garnier, s.f. 
Algunas de las fábulas empiezan y terminan con verso aislado de este tipo:

Verso inicial: «Le lion dans sa tête avoit une entreprise.»

Verso final: «Il n'est rien d'inutile aux personnes de sens.»

(Le Lion s'en allant en guerre).

Verso inicial: «Un homme vit une Couleuvre.»

Verso final: «Parler de loin ou bien se taire.»

(L'Homme et la Couleuvre)

Esta tradición alcanza, naturalmente, aunque en menor grado, a los fabulistas españoles. Damos como muestra algunos versos iniciales y finales de Félix María Samaniego. ${ }^{14}$

Versos iniciales:

«A dos amigos se apareció un oso.»

(Los dos amigos y el oso)

«Amaba un león a una zagala hermosa»

(El león enamorado)

«Un águila anidó sobre una encina»

(El águila, la gata y la jabalina)

Versos finales:

«¡Oh preocupación, y cuánto puedes!»

(El charlatán y el rústico)

«También hay para pícaros engaño»

(La zorra y la cigüeña)

«El útil bien es la mayor belleza»

(El ciervo en la fuente)

${ }^{14}$ Las citas de Samaniego e Iriarte proceden de la edición Fábulas completas de Samaniego e Iriarte, Paris, Garnier, 1881. 
Versos iniciales en las fábulas de Iriarte:

«Había en un corral un gallinero»

("El gallo, el cerdo y el cordero")

«Tuvo Esopo famosas ocurrencias»

("El ratón y el gato")

Versos finales:

«Pues más debe estudiar el que más sabe»

("El ruiseñor y el gorrión")

«¿Qué será de nosotros, desdichados?»

("Las ranas al sol").

Pueden asimilarse a este tipo de versos otros que «encuadrados por interrogaciones o admiraciones» adquieren también cierta autonomía:

«iOh desmayo dichoso!»

(Fray Luis, "A Francisco Salinas”, posición inicial)

«¿Hay más extraño rigor?»

(Lope, Los embustes de Celauro, I, XX)

«¿Qué mucho si so de tiera?»

(Tirso, El colmenero divino, I)

o en situación paralelística:

«¡Oh! ¡Quién se desengañara!»

«¡Oh! ¿Quién sin temor se viera!»

(Calderón, Peor está que estaba, III)

«¿Que no he de volver a hablarte!»

«iQue no he de volver a verte!»

(Id., El acaso y el error, I) 
También se encuentran endecasílabos con las mismas características:

«¿Qué enemigo rendido no es esclavo?»

(Id., Gustos y disgustos, II: final de tirada en silva)

«¡Cómo eslabona el cielo nuestros males!»

(Id., La dama duende, III. Final de tirada en silva)

Y cómo resistir a citar el tan famoso verso de Miguel Hernández en El rayo que no cesa, en situación final de soneto:

«¡Cuánto penar para morirse uno!»

Estos ejemplos vienen a confirmar la opinión de Joseph Hrabák: «el verso es con respecto a la sintaxis, una unidad autónoma». ${ }^{15}$

Pueden incluirse aquí las réplicas en el teatro, cuando se condensan en un solo verso, en cualquiera de sus posibilidades: afirmativa, interrogativa o exclamativa; o también a modo de sentencia:

«iOh industria, cuánto aprovechas!»

(Lope, Los embustes de Celauro, I, esc. XV)

«Triste del que vive amando.»

(Id, II, esc. VIII)

«Amor labrador no olvida.»

(Tirso, El Melancólico, I, esc. XII)

«La mocedad nunca es sabio»

(Id, La elección por la virtud, III, esc. VIII)

«No hay fuerza que venza a amor.»

(Calderón, La banda y la flor, III).

${ }^{15}$ Joseph HRABÁK, O charakter českého verse. Citado por O. BELIC in En busca del verso español, op. cit., 42. 
$2^{\circ}$ ) La posibilidad de considerar algunos versos como aislados en cierto modo del conjunto del poema la dan aquellos que aparecen, recordando en esto las expresiones refranescas o sentenciosas que encabezan el poema o la estrofa al principio o se sitúan al final, enmarcados por punto y aparte y como expresión de evidencia de lo que se desarrolla después, o de lo que se ha desarrollado antes. También tiene relación con esto la opinión de Joseph Hrabák cuando afirma que «si se nos presenta un verso aislado, tiene que ser señalado como tal por alguno de los medios convencionales, por ejemplo por su forma gráfica». ${ }^{16}$ Creemos que esos medios convencionales pueden ser, entre otros, la puntuación y/o la separación mediante espacios. He aquí algunos casos: el poema "Te quiero", de Luis Cernuda en La realidad y el deseo; aparece esta expresión como título de poema, pero también como verso aislado inicial, encuadrado por punto y separado por espacio. ${ }^{17}$ Otros ejemplos espigados en el mismo poeta:

Verso inicial de poema: «Yo fui.»

Verso final del poema: «He sido.»

(IV de Donde habite el olvido)

con expresión sintáctica mínima pero completa:

Verso final: «No sabes, no sabes.»

Verso final:«No, no es el amor quien muere.»

(Id., XII)

Verso inicial:«El mar, y nada más.»

(de "El joven marino").

Se podrían citar numerosos casos semejantes. Baste con añadir unos ejemplos de La destrucción o el amor, de Vicente Aleixandre, muy próximos en forma y significado a los de ${ }^{16}$ Joseph HRABÁK, Introducción a la teoría del verso, Praha, 1970, 8. Citado por Oldrich BELIC, op. cit, 11.

17 Luis CERNUDA, La realidad y el deseo, Clásicos Castalia 125, 1991, 160. 
Cernuda:

«Se querían.», en posición inicial de poema;

«Sí, te he querido como nunca.», en la misma posición.

Este tipo de verso corto inicial y aislado debe tener antecedentes. Uno de ellos, también de cuatro sílabas, se encuentra en el poema 14 de La frente pensativa de Juan Ramón Jiménez. Ese verso es:

«Se quejaba.» ${ }^{18}$

y deben existir, naturalmente, otros.

Pueden darse también como ejemplos los versos finales de poema que quedan aislados de éste por terminar el verso anterior en punto y estar en posición final. Jorge Guillén ${ }^{19}$ utiliza a veces este recurso:

Soneto "Amanece, amanezco"; verso final:

«Todo lo inventa el rayo de la aurora.»

Soneto "Hacia el poema":

«Hacia una luz mis penas se consumen.»

Soneto "Profundo espejo":

«La verdad inventaba a sus expensas.»

Soneto "Siempre en la isla":

"¿Ves? A tus pies la isla se reanima.»

Soneto "Para ser":

«Amor: te necesito en el asedio.»

Soneto "En suma":

«Creo en la creación más evidente.»

${ }^{18}$ In Segunda antolojía poética, Madrid, Espasa-Calpe, 1959, p. 191.

${ }^{19}$ Citamos por la edición de Cántico, Barcelona, Barral Editores, 1977. 
En la obra de Guillén es relativamente frecuente encontrar versos iniciales o finales separados del siguiente o del anterior por punto final, quedando así esos versos como ensalzados en el conjunto del poema. He aquí algunos casos:

Verso final de "Música, sólo música":

«Todo está cumplido.»

Verso final de "El diálogo":

«Fluía la mañana por el diálogo.»

Verso final de "Anillo":

«¿Por vencida te das ahora, Muerte?»

Verso final de "Desnudo":

«iOh absoluto Presente!»

Las décimas guillenianas utilizan este mismo tipo de versos aislados:

Décima "A eso de las cuatro" en posición final:

«Sin miedo miré al oriente.»

Décima "Dinero de Dios", posición inicial:

«Pasa cerca, le adivino.»

Décima "Generosa", posición final:

«Valga el suspiro que exhalo.»

Décima "Verso es amor", posiciones inicial y final:

Inicial: «El río diseña un arco.»

Final: «El río se da y perdura.»

Décima "El niño dice...", posición inicial:

«¿Qué dice? Ni un balbuceo.»

Décima “En plenitud”, posición final: 
«¿Qué es ventura? Lo que es.»

etc.

Hay en Cántico muchísimos otros casos de versos aislados entre dos puntos. He aquí algunos de ellos:

Inicial: «¡Cima de la delicia!»

Id.: «Un resto de crepúsculo resbala.»

Id.: «Oigo crujir una arena.»

Final: «Va a sonar una armonía.»

Id.: «Es tenaz la esperanza con paisaje.»

Id.: «Creo en la creación más evidente», ya citado.

Id.: «Sí, tu niñez, ya fábula de fuentes.»

Tampoco escasean versos contiguos en los que cada uno tiene un comportamiento separado:

De "Sol en la boda":

"Alrededor se consuma el verano.

Es un anillo la tarde amarilla.»

De "Amor a una mañana":

«Se pierde quien se lo pierde.

¡Qué mío el campo tan verde!»

De "La estrella de Venus":

«Un tren: silbido, ráfaga.

Desgarrado el presente!

Lejanías humean.»

De "Navidad":

«Miserables los hombres.

Dura la tierra.»»

De "Hacia el poema": 
«El son me da un perfil de carne y hueso.

La forma se me vuelve salvavidas.

Hacia una luz mis penas se consumen»

En Cántico aparecen algunos versos separados por punto y espacio del poema a que pertenecen. Nadie puede dudar de que si Jorge Guillén adopta esa disposición, es por una razón profunda, consciente o no, dando al verso un realce, una disposición a la autonomía que es preciso reconocer: El poema "Además" tiene como versos inicial y final dos aislados por punto y espacio:

Verso inicial: «Júbilo al sol. ¿De quién? ¿De todos? Júbilo.»

Verso final: «Todo es prodigio por añadidura.»

Casi todos estos ejemplos tienen el verbo en presente. También ese rasgo debe obedecer a una razón profunda en el poeta.

No podemos prescindir de citar el conocido verso de Mallarmé ${ }^{20}$ aislado por punto y aparte anterior, y que cobra en su posición final de estrofa, un relieve especial:

“Je suis hanté. L'Azur! L'Azur ! L'Azur ! L'Azur!» ("L'Azur")

También ofrece este mismo poeta, esta vez aislados por punto y espacio, en el interior del poema, tres variantes de un mismo verso:

"Allah le regardait d'un œil indifférent.»

«Allah le regardait, froid comme un dieu de marbre.»

«Dieu fronça le sourcil et lança son tonnerre.»

("La colère d'Allah", vv 22, 39 y 60)

En 20 poemas de amor y una canción desesperada de Pablo Neruda, aparecen repetidas veces versos aislados por punto del anterior, en general en posición final del grupo de versos a que pertenecen. Tres veces aparece un verso aislado separado de su

${ }^{20}$ Citamos de la edición de La Pléiade, Euvres complètes, 3 vols, Paris, 1998. 
contexto por espacio anterior y siguiente e intercalado en la serie. Se encuentran en el poema "8 Abeja blanca zumbas..." Este poema se compone de nueve pares de versos separados entre sí por espacio, pero ademas cada tres pares de versos se intercala otro encuadrado también por espacios:

«Ah silenciosa!»

El poema “17, Pensando, enredando sombras..." termina con otro verso separado:

«¿Quién eres tú, quién eres?»

Aunque escasos, algunos versos de final de fábula aparecen también en La Fontaine, separados por espacio, siempre con ese significado de sentencia extraída del ejemplo desarrollado:

«En toute chose il faut considérer la fin.»

(Le Renard et le Bouc)

«Laissez dire les sots; le savoir a son prix.»

(L'avantage de la science)

«Il n'est pas malaisé de tromper un trompeur.»

(L'enfouisseur et son compère)

«Plus fait douceur que violence.»

(Phébus et Borée)

y algunos otros más.

Versos separados por espacios del cuerpo del poema se encuentran igualmente en la poesía francesa posterior. Mallarmé separa el verso final de cierre de una serie de tercetos por espacio en el poema "Le Guignon" y también en los poemas "Aumône" y "Haine de pauvre". ${ }^{21}$ Un caso curioso se presenta en el poema "Le lierre maudit. Ballade" compuesto de doce estrofas (ABAB-

${ }^{21}$ Op. cit., I, 191-194. 
CDCD) cuyo verso final en todas ellas es el verso aislado:

«Le sylphe dort aux fleurs de la bruyère.» 22

Guillaume Apollinaire utiliza este recurso de aislamiento repetidas veces. Así en "Zone", el poema inicial de Alcools, se lee:

«À la fin tu es las de ce monde ancien.»

Salta enseguida un espacio y sigue sin aparente lazo de sentido :

«Bergère ô tour Eiffel le troupeau des ponts bêle ce matin»

Salta de nuevo un espacio y continúa:

«Tu en as assez de vivre dans l'antiquité grecque et romaine»

E igualmente, el famoso el verso final de "Nuit rhénane", también separado por espacio del cuerpo del poema:

«Mon verre s'est brisé comme un éclat de rire»

En "Rhénane d'automne" el poeta dispone sus versos en grupos o estrofas a los que sigue un verso separado. Estos versos separados son:

«L'air tremble de flammes et de prières»

y también:

«Puis dans le vent nous nous en retournames»

Otros casos en Apollinaire; del poema "Il y a", en posición final:

${ }^{22}$ Citamos por la edición La Pléïade. 
«Je n’ai jamais vu Carcassonne»

o en "Poèmes à Lou":

«O mon unique amour et ma grande folie.»

Y más próximo a nosotros en el tiempo, dos ejemplos de René Char de su poema "Neuf merci pour Vieira da Silva". ${ }^{23}$ Es un poema en forma libre. $\mathrm{El} \mathrm{n}^{\circ}$ III se compone por dos versos aislados de los anteriores y los siguientes, pero también entre sí por un asterisco. El título común de estos dos versos es «C'est bien elle» y dicen así:

«Terre de basse nuit et de harcèlements.» $*$

«Nuit, mon feuillage et ma glèbe.»

Poemas con verso final aislado por punto se encuentran en muchos poetas y sería impropio aquí realizar un sondeo metódico en un autor o en una época. Los ejemplos aducidos, y los que siguen deben ser suficientes para ilustrar esta investigación.

Aportamos dos ejemplos de versos finales separados por espacio, sacados de El destino de la melancolía de Carlos Pinto Grote:

«Todo era ayer. Sin pausa.» (XII)

«Sólo el amor advierte su presencia.» (XXXVI) ${ }^{24}$

uno de Dionisio Ridruejo, separado y final:

«Porque la aurora es el deber del hombre..» 25

${ }^{23}$ René CHAR, Le Matinaux suivi de La parole en archipel, Paris, Poésie Gallimard, 1962, 158.

${ }^{24}$ Carlos PINTO GROTE, El destino de la melancolía, Santa Cruz de Tenerife, 1996.

${ }^{25}$ Dionisio RIDRUEJO, Primer libro de amor, Cstalia 73, 1979, 163. 
Claudio Rodríguez, ${ }^{26}$ que no suele emplear versos aislados, incluye uno final también separado por espacio, en "Noche abierta":

«Bienvenida la noche con su peligro hermoso.»

He aquí algunos ejemplos de versos finales aislados por punto, encontrados en la obra de Luis Antonio de Villena: ${ }^{27}$

« $\mathrm{Y}$ el amor continúa palpitando en la carne!»

("El durmiente")

«Vivir, sentir, gozar. Sin más problemas.»

("El ciruelo blanco y el ciruelo rojo")

«La sangre y el sudor nunca fueron tan dulces.»

("Vestuario")

La poesía francesa contemporánea ofrece casos de versos aislados con no poca frecuencia. Philippe Jacottet en un mismo poema ("Lettre du vingt-six juin") ${ }^{28}$ utliza un verso inicial aislado por punto y un verso final aislado por punto y espacio, separado además por asterisco. Son los siguientes:

Verso inicial:

«Que les oiseaux vous parlent désormais de notre vie»

Verso final:

«Lorsque nous parlerons avec la voix du rossignol...»

Más curiosos son los casos que aparecen en "Leçons" donde alguna vez el poema termina no sólo con un verso separado, sino con dos separados además entre sí:

${ }^{26}$ Claudio RODRÍGUEZ, Desde mis poemas,Madrid, Cátedra 175, 1983.

${ }^{27}$ Citamos de Luis Antonio DE VILLENA, Poesía 1970-1984, Madrid, Col. Visor de Poesía 233, 1988.

${ }^{28}$ Citamos por la edición Philippe JACOTTET, Poésie 1946-1967, Paris, Poésie/Gallimard, 2001. 
Verso anteúltimo separado por espacio anterior y siguiente: «Il ne pèse presque plus.»

Verso último separado del anterior por espacio:

«La terre qui nous portait tremble.»

El último poema de este apartado y también del libro antológico del que citamos merece ser copiado íntegramente para mayor claridad. Cuatro versos, el inicial, y tres interiores, están separados por sus adyacentes:

«Toi cependant,

ou tout à fait effacé,

et nous laissant moins de cendres

que feu d'un soir au foyer,

ou invisible habitant l'invisible,

ou graine dans la loge de nos cœurs,

quoi qu'il en soit,

demeure en modèle de patience et de sourire

tel le soleil dans notre dos encore

qu'éclaire la table, et la page, et les raisins.»

Es posible que para el poeta mismo no resulte fácil explicar el porqué de esta disposición que obedece sin ninguna duda a un instinto seguro.

Más próximo en el tiempo, Eduardo Fraile Valles incluye en su libro con la posible excepción de mí mismo, ${ }^{29}$ poemas compuestos de frases numeradas, algunas de las cuales resaltan por su aislamiento, sin puntuación final. Así en "11 poemas de amor":

${ }^{29}$ Eduardo FRAILE VALLES, con la posible excepción de mi mismo, Valladolid, Col.

Tansonville 1, 2001. 
«2 esta dulce necesidad de no tenerte»

«7 te fuiste desnudando de mí tan dulcemente»

(en cursiva en el texto)

«11 ...no ser un dos, sino dos unos...»

(id)

Este libro recoge en igual forma de frases numeradas un poema anteriormente publicado en forma de pequeño cuadernillo, en el que cada uno de los versos ocupaba una página. Es el poema "De las cosas" que ahora ya, incorporado en el libro, aparece en frases seguidas y numeradas:

"1 Las cosas son contingentes."

"2 Una cosa es todas las cosas."

etc. La 25, en "Apéndice" dice:

«25 Las cosas prefieren encontrar ellas mismas el modo de suceder.»

Un experimentador de la métrica como lo fue Julio Herrera y Reissig, ${ }^{30}$ cronológicamente anterior, ofrece un ejemplo que conviene citar. El poema "Las plagas" de "Las pascuas del tiempo" se compone de ocho estrofas más o menos regulares que terminan con un verso separado del anterior por punto, con una variante cada vez. Son, por orden de aparición en el poema, los siguientes:

«Ya la noche de tus ojos ha caído sobre mí!» (est. 1)

«El vértigo de tus ojos ha caído sobre mí!» (est. 2)

«El invierno de tus ojos ha caído sobre mí!» (est. 3)

«La perdición de tus ojos ha caído sobre mí!» (est. 4)

«La tempestad de tus ojos ha caído sobre mí!» (est. 5)

«La maldición de tus ojos ha caído sobre mí!» (est. 6)

$\overline{{ }^{30}}$ Las citas siguen la edición Julio HERRERA Y REISSIG, Poesía completa y prosas, ALLCA, Colección Archivos, Madrid (y otros lugares), 1998. 
«El infierno de tus ojos ha caído sobre mí!» (est. 7) «La eternidad de tus ojos ha caído sobre mí!» (est. 8)

Hay en estos versos finales de estrofa una gradación desde "noche" a "eternidad" que establece entre ellos una relación de parentesco y de fraternidad que conducen a pensar si el concepto de serie no se debe ampliar a esa otra serie que forman algunos versos del poema entre sí. Es el caso aquí de la "serie" de estos finales de estrofa. Otra modalidad vamos a encontrar en los finales de los sonetos del libro A la pintura de Rafel Alberti.

La introducción de variantes en un mismo tipo de verso, le da a cada uno un realce singular $\mathrm{y}$, cuando son contiguos, un carácter de letanía dentro de la cual cada uno de ellos se erige como verso único. Carlos Edmundo de Ory utiliza este recurso tratando los versos sin puntuación, como si la autonomía de cada uno fuese una evidencia. He aquí algunos casos sacados del libro Miserable ternura: ${ }^{31}$

Posición inicial:

«Palabra tú eres acto o cállate

Poesía verdadera eres errante» (p. 48)

Id.

«Oye amiga oye amante óyemeóyeme

Me levanté en tu cuerpo me caí

Tengo tu carne de ternura eterna» (p. 52)

Ángel González termina uno de sus poemas con verso no sólo aislado por espacio, sino también por paréntesis:

«(Me voy soñando. Vengo de soñar.)» $\rangle^{32}$

y en su libro Los Asombros de Julio Alfredo Egea, ${ }^{33}$ el poema "Encuentro con el mar" termina en verso separado por espacio del cuerpo del poema:

${ }^{31}$ Carlos Edmundo DE ORY, Miserable ternura, Madrid, Poesía Hiperión, 1981.

32 Ángel GONZÁLEZ, Palabra sobre palabra, Barcelona, Seix Barral, 1992, 27.

33 Julio Alfredo EGEA, Los asombros, Valdepeñas, Col. "Juan Alcaide", Tercera época, $N^{\circ} 8,1996$. 
«Supe después de los acantilados»

Todo esto parece corroborar la opinión de Belic quien encuentra que «no sería difícil hallar versos que, aunque sacados de sus contextos, no pierden nada de su potencia semántica, tal vez al contrario». ${ }^{34}$ Y cita como ejemplos los tan conocidos "Collige, virgo, rosas" de Magno Ausonio; "To be or not to be» de Shakespeare y un hemistiquio de Corneille: «Je suis jeune, il est vrai». Estos ejemplos vienen a contradecir la opinión de Balbín que considera que el verso separado de su contexto pierde su valor comunicativo. ${ }^{35}$

$3^{\circ}$ ) Muchos tratadistas, como se ha visto, sólo consideran verso a aquel que se encuentra incluido en una serie, sin que el concepto de serie quede totalmente definido. Se sobreentiende que la serie es un conjunto de versos que se siguen, que forman un poema en el que algunas formas son recurrentes: número de sílabas, rima, tipo de estrofa, etc. Opinión contra la que se expresa Daniel Devoto en su trabajo ya mencionado: «más contestable es todavía - dice- pretender que la repetición es la condición sine qua non de su existencia». ${ }^{36}$ Se pregunta también si puede considerarse serie, por ejemplo, una silva que dispone sus versos libremente en el poema sin que la recurrencia resulte evidente.

Por otra parte también es posible que el concepto de serie no requiera rigurosamente la recurrencia en un poema, sino de alguna manera en un conjunto de poemas. Podemos imaginar perfectamente un conjunto de poemas que empiezan o terminan

\footnotetext{
${ }^{34}$ En busca del verso español, op. cit., 43.

${ }^{35}$ Rafael BALBÍN LUCAS, Sistema de ritmica castellana, Gredos, Madrid, 1968, 400: «tanto porque el verso aislado no se da con validez poética en el hecho literario, como porque la unidad versal no tiene de suyo unidad sintáctica ni por ello virtualidad estilística propia y plena. El verso separado de su contexto estrófico, pierde normalmente - como pez sacado del agua- su vitalidad comunicativa; y queda reducido a ser un segmento inorgánico de la cadena fónica y de la secuencia lingüística». Citado por O. BELIC, op. cit., 41.

${ }^{36}$ Op. cit., 5, 1980 / 1982, 78.
} 
con un mismo verso, o con alguna variante de ese verso, encargado de una expresión que viene a ser tema a desarrollar o conclusión de lo expuesto, o destino, dedicatoria, homenaje a alguien o a algo.

En el espléndido libro de Rafael Alberti $A$ la pintura ${ }^{37}$ se incluyen, para definir los colores, versos aislados con formas sintácticas completas o incompletas pero con esa autonomía de que se ha hablado y que ya es preciso subrayar. He aquí algunos de ellos:

AZUL:

1 «Llegó el azul. Y se pintó su tiempo.»

2 «¿Cuántos azules dio el Mediterráneo?»

3 «Venus, madre del mar de los azules.»

5 «El azul Edad Media delicado.»

12 «Venecia del azul Tiziano en oro.»

13 «Roma de los azules Poussin entre los pinos.»

14 «Me enveneno de azules Tintoretto.»

23 «Explosiones de azul en las alegorías.»

27 «Dieron las Baleares su azul a la Pintura.»

ROJO:

2 «Lucho en el verde de la fruta y venzo.»

4 «Pleno rubor redondo en la manzana.»

10: «Pluma en las alas de Luzbel, ardiendo.»

17 «¿En la rosa? Diverso, pero único.»

20 "Una rosa con escarcha, de Velázquez.»

21 «Otro -Goya- con aire diluído».

23 «La niña rosa -ioh sueño-de Rosales.»

24 «Bajé hasta el rosa rosa de Picasso.»

25 «Rojo, contra el azul, de una bandera.»

31 «Como el grana fugaz de una amapola.»

AMARILLO:

5 «Gualda de sol -pinturas- de Pompeya.»

13 «Seca piel de arrugado pergamino.»

15 «El pálido amarillo de la muerte.»

16 «Marfil oculto dentro de la carne.»

${ }^{37}$ Utilizamos la edición de A la pintura, Buenos Aires, Editorial Losada 247, 1953. 
18 «Aparezco de pronto en la tormenta.»

22 «El amarillo Rembrandt revelado.»

24 «Temo al azul porque me pone verde.»

$31 \ll$ El amarillo cromo satinado.»

VERDE:

2 «Tengo otro nombre siempre: Primavera.»

7 «Un verde sumergido en las aguas del tiempo.»

18 «El verde solitario de la muerte.»

29 «Cézanne me corta, Renoir me envuelve.»

NEGRO:

1 Dio su revés la luz. Y nació el negro.»

9 «Un negro como flor de la alegría.»

10 «Hosannas en los negros de Tiziano.»

15 «Fui en el retrato majestad y orgullo.»

16 «Gloria y honor severos del ropaje.»»

17 «Monumento callado de la muerte.»

20 «El negro olor de cirios apagados.»

21 «Negro negro Ribera negro negro.»

22 «Negro misa solemne Zurbarán.»

23 «El negro misterioso, secreto, de las minas.»

24 «El alma negra junto al rojo, en llamas.»

31 «Negro de pesadilla en los románticos.»

BLANCO:

3 «Blanco de las atónitas columnas asombradas.»

8 «Blanco Cádiz de plata en el recuerdo.»

9 «Yo soy el hijo de la cal más pura.»

12 «Soy el más albañil de los colores.»

17 «De pronto caigo como traje o nube.»

21 «Espuma de la mar, galopadora.»

23 «Y sobre algunos lienzos, fugaz blanco paloma.»

26 «Blanco de aparición, blanco del éxtasis.»

27 «Blanca gorguera llama blanca Greco.»

33 «Recordad que también yo soy la rosa.»

Los versos citados, numerados, forman parte de conjuntos en los que esos versos $-\mathrm{y}$ otros grupos formados por dos, tres o cuatro versos- suelen ser en su mayor parte endecasílabos. 
Bien pudiera ser que, como ya se ha apuntado más arriba, la serie se establezca, no únicamente en el poema, sino entre versos que perteneciendo a poemas distintos, tienen entre sí algo compartido en el asunto de que se trata y/o en la expresión. Esos versos se aíslan del poema al que pertenecen para establecer una relación de parentesco con versos incluidos en otros poemas. Apoya, además, esta pertenencia a la misma familia, el hecho de que esos versos se sitúen siempre en igual posición y adopten una estructura lingüística paralela.

Se trata de sonetos del mismo libro en que se utiliza varias veces la fórmula «A ti» como arranque de verso y de composición, y tambien de estrofa y en algún caso, como en el soneto que sigue, incluso en cada uno de los versos de una estrofa:

\section{A LA PINTURA}

«A ti, lino en el campo. A ti, extendida superficie a los ojos, en espera.

A ti, imaginación, helor u hoguera, diseño fiel o llama desceñida.

A ti, línea impensada o concebida.

A ti, pincel heroico, roca o cera, obediente al estilo o la manera, dócil a la medida o desmedida;

A ti, forma; color, sonoro empeño porque la vida ya volumen hable, sombra entre luz, luz entre sol, oscura.

A ti, fingida realidad del sueño.

A ti, materia plástica palpable.

A ti, mano, pintor de la Pintura.»

También se pueden esgrimir estos versos contra la afirmación de que el verso debe ser una expresión lingüística completa, pues muchos de los versos citados más arriba como definiciones de color, y éstos del soneto carecen precisamente de esa exigencia. Podríamos preguntar, ¿A ti dedico? ¿A ti declaro? ¿A ti me dirijo?, etc. Y no sólo en los versos separadamente, sino en el soneto completo. 
Quienes consideran que el verso, para serlo, tiene que formar parte de una serie, tienen aquí excelentes ejemplos de recurrencia. Pero ahora nos interesa insistir en que el concepto de serie puede ser matizado a partir de la aparición de una misma estructura como verso final de distintos sonetos, con un comportamiento que le enriquece con cierta independencia respecto a los otros. Sería lícito establecer en este caso un concepto de serie transversal de modo que cada uno de esos versos realza su parentesco con los otros finales de los otros sonetos. El verso final del soneto citado adopta una repartición tripartita: «A ti / mano /pintor de la Pintura». La Pintura, en posición final, con mayúscula. Esta estructura reaparece en cada final de soneto. Son los siguientes:

A LA RETINA: A ti, / fuente inmortal / de la Pintura. A LA MANO: A ti, / alma del jardín / de la Pintura. A LA PALETA: A ti, / lecho y crisol / de la Pintura. A LA PINTURA MURAL: A ti, / inicial viril / de la Pintura. AL LIENZO: A ti, / ángel salvador / de la Pintura. AL PINCEL: A ti, / esbelto albañil / de la Pintura. A LA LÍNEA: A ti, / andamio y sostén / de la Pintura. A LA PERSPECTIVA: A ti, / brida y timón / de la Pintura. AL CLAROSCURO: A ti, / Rembrandt febril / de la Pintura. A LA COMPOSICIÓN: A ti, / soplo y razón / de la Pintura. AL COLOR: A ti, / gloria y pasión / de la Pintura. AL ROPAJE: A ti, / fiel tejedor/ de la Pintura. A LA LUZ: A ti, / espejo y fanal / de la Pintura. A LA SOMBRA: A ti, / claro Luzbel / de la Pintura. AL MOVIMIENTO: A ti, / libertador / de la Pintura. AL DESNUDO: A ti, / Venus en flor / de la Pintura. A LA GRACIA: A ti, / yo no sé qué / de la Pintura. A LA ACUARELA: A ti, / río hacia el mar / de la Pintura.

Sólo un soneto modifica el verso final. Es el titulado "A LA DIVINA PROPORCIÓN" que termina así: A ti,/ divina proporción de oro. ${ }^{38}$

${ }^{38}$ Carlos Edmundo de Ory, en su Miserable ternura, op. cit. dedica a los colores una serie de versos que copiamos como curiosidad por la semejanza de asunto con los de Alberti: 
Versos aislados por espacios aparecen en muchos poetas. Juan Eduardo Cirlot ${ }^{39}$ los emplea con frecuencia:

De "Bronwyn":

«Estoy cansado de estar muerto y ser.»

«En tus ojos, cayendo, un gran mar se levanta.»

«Lo espantoso es sencillo y está siempre muy cerca.»

«Mi corazón es blanco y no se queja.»

«La distancia no es más que una palabra.»

«Las ruinas de las runas nos circundan.»

y otros.

El verso aislado por espacios, pero ahora en el interior del poema, aunque quizá con menor frecuencia, también aparece:

«Danos, Tarzán, tu selva que nos salve.» de Clamor a fondo perdido de Salustiano Masó. ${ }^{40}$

Los versos aislados por puntuación conducen a considerar el caso de la esticomitia. Cuando un poeta dispone sus versos de tal modo que cada uno de ellos se basta a sí mismo como unidad de significado, por algo será. El poeta da así a cada verso un pedestal sobre el cual se erige como individuo solo. En la mayoría de los casos de esticomitia los versos van separados por

\footnotetext{
"Mi vida era una hoja inválida

y vino el verde a darme más tamaño

Supe el rojo ardiendo que rugía

El amarillo sabio invistióme observancia

El azul la pureza que es azul

El rosa me ofrecía la esperanza

El gris barbilampiño la tristeza

Finiquita acuarela deja al negro

impositivo llavearte muerte.

Después de todo yo coloro vida yo adoro los colores."

Una coincidencia como se dan tantas en la creación literaria.

${ }^{39}$ Eduardo CIRLOT, Obra poética, ed. de Clara Janés, Madrid, Cátedra 142, 1981.

${ }^{40}$ Salustiano MASÓ, Clamor a fondo perdido, Madrid, Libertarias / Prodhufi, 1995, 272.
} 
una puntuación fuerte, el punto. Pero también puede darse con versos que terminan con otro tipo de puntuación.

De 20 poemas de amor y una canción desesperada de Pablo Neruda, copiamos del poema "5 Para que tú me oigas", esta serie esticomítica:

«El viento de la angustia aún las suele arrastrar.» «Huracanes de sueños aún a veces las tumban.» «Escuchas otras voces en mi voz dolorida.» «Llanto de viejas bocas, sangre de viejas súplicas.» "Ámame, compañera. No me abandones. Sígueme.» «Sígueme, compañera, en esa ola de angustia.» «Pero se van tiñendo con tu amor mis palabras.» «Todo lo ocupas tú, todo lo ocupas.»

Entresacamos ahora algunos casos de Juan Eduardo Cirlot: De "Canto de vida muerta":

«La muerte era este beso exasperado, la muerte era este muro deslumbrante, la muerte era este almendro florecido, la muerte era mi voz enamorada, la muerte era el recuerdo, era la mano, la muerte era mi verde golondrina,»

y continúa introducciendo una subvariante:

«no este cisne sin luz deshabitado, no este absorto fulgor que no varía, no esta forma perpetuamente sola, no esta sangre sin sangre y sin latido.»

La esticomitia, como se ve, favorece la anáfora: De "Nunca":

«hay una casa verde, hay una puerta blanca, hay una luz que tiembla $[\ldots]$ 
Hay una casa verde, hay tus manos delgadas, hay mi amargura sola, al final del paisaje.»

"De Susan Lenox":

«Se llamaba Susana por la tarde, se llamaba Susana al mediodía, se llamaba Susana por la noche. Susana se llamaba por el alba.»

De "Elegía sumeria":

«Mi voz hecha de torres y relámpagos negros, mi voz de combatiente por una guerra antigua, mi voz de sacerdote con ojos de jaguar $[\ldots]$ Sumeria es un sagrario de amor asesinado; Sumeria es una boca de espigas y relámpagos.»

De "44 sonetos de amor":

«Princesa prisionera de la nada, princesa prisionera de la suerte, princesa prisionera de la muerte, princesa del abismo en la mirada,» etc.

La esticomitia no es novedad moderna. Se dijo primeramente de los versos solos en el diálogo de la escena que son muy abundantes; también del diálogo en que cada réplica es un hemistiquio. Pero ampliado ese concepto a los versos contiguos que se bastan a sí mismos como expresión de un significado, pueden rastrearse desde los orígenes, tanto en estrofas anafóricas como no. En el Libro de Buen Amor:

«Sey como la paloma limpio e mesurado; sey como el pavón, loçano, sosegado; 
sey cuerdo e non sañudo, nin triste nin irado;

en esto se esmera el que es enamorado.» (est. 563)

o bien

«Non se mienbran algunos del mucho bien antigo;

quien a mal omne sirve, senprel sera mendigo;

el malo a los suyos non les presta un figo;

apenas quel pobre viejo falla ningund amigo.» (est. 1366)

En Fray Luis de León:

«iOh campos verdaderos!

¡Oh prados con verdad frescos y amenos!

¡Riquísimos mineros!

¡Oh deleitosos senos!

¡Repuestos valles de mil bienes llenos!»

(A Diego Olarte)

y entre los poetas del xx, José Bergamín ${ }^{41}$ en series anafóricas:

«Mentira es el cielo azul.

Mentira es el agua clara.

Mentira lo que tú dices.

Mentira lo que te callas.

Mentira es que haya otro mundo.

Mentira es que éste se caba;

Mentira que tú lo creas.

Mentira que tengas alma. »

(Poema 361 de "Canto rodado")

$4^{\circ}$ ) El verso solo, separado de los otros del mismo conjunto en página que él únicamente ocupa, es de frecuencia menor, pero existe. También aquí debemos respetar la voluntad del poeta y aceptar que cuando él utiliza una página entera para un solo

${ }^{41}$ José BERGAMín, Antología poética, Ed. de Diego Martínez Torón, Madrid, Clásicos Castalia 227, 1997. 
verso, sus razones tendrá. El verso solo aparece así, sin título, como eslabón suelto de su conjunto, como puente de enlace también entre dos series. Por su forma puede asemejarse o no a los otros versos del poema o del conjunto.

Ya Mallarmé en su poema 'Un coup de dés jamais n'abolira le hasard" aísla solo en página blanca el verso

«plume solitaire éperdue». ${ }^{42}$

Eduardo Fraile Valles en el $\mathrm{n}^{\circ} 16$ de P.O.E.M.A.S., ${ }^{43}$ ya en 1995, daba versos aislados en página, pero relacionados con el conjunto:

«sabes a copa de cristal con mi mirada dentro»

y este otro:

«me pides ángeles y te lleno la boca de palabras»

El caso más reciente que hemos encontrado se encuentra en el libro El malentendido de Elena Pallarés. ${ }^{44}$ Se trata de un libropoema distribuido de modo irregular en las páginas en fragmentos sin numeración ni títulos, generalmente endecasílabos, de extensión variable. Versos solos en página son los siguientes:

Pág. 40: «Tan niña y con el nombre hecho pedazos».

Pág. 41 «Al margen anotó: "La muerta en flor».

Pág. 73 «Palabra hecha de aire, vuelve al aire».

Pág. 102 «La traducción: un pacto con el mal».

Pág. 106 «La traducción equivoca el oráculo».

Pág. 112 «El libro tiene la última palabra».

42 Op. cit. I, 378.

${ }^{43}$ Eduardo FRAILE VALLES, P.O.E.M.A.S. 16, Valldolid, 1995.

44 Elena PALLARÉS, El Malentendido, Valladolid, Col. Cortalaire 40, Fundación Jorge Guillén, 2002. 
$5^{\circ}$ ) El último peldaño de esta larga ascensión será el versopoema.

Laurence Braysse ${ }^{45}$ adelanta los versos de Bécquer:

«¿Comprendes ya que un poema cabe en un verso?»

diciendo que «la rima XXIX enuncia el deseo del poema semejante a un verso único» y considera que «el Verso para una amiga [de Manuel Altolaguirre] realiza el sueño del poemaverso: en 1930, Altolaguirre edita un pliego de seis páginas, con una palabra en cada una». La publicación es de 1931. Se trata en realidad de un endecasílabo distribuido de tal forma que cada palabra ocupa una página. Y en una carta de este poeta a Bernabé Fernández Canivel (14 de octubre de 1957) «se materializa el ansia por el verso-poema». Se trata, por lo tanto de un "deseo", de un "ansia" por alcanzar ese verso-poema tan huidizo.

Pero el verso-poema existe ya en Apollinaire, con su título y situado en página solamente ocupada por él. Es el poema "Chantre" que dice así:

«Et l'unique cordeau des trompettes marines»

aunque el autor no lo denomina poema.

Hay que saltar en el tiempo y en el espacio para encontrar poemas que son un solo verso cada uno y denominados como tales por su autor. Son los "Poemas interminables" incluidos en el libro Lee sin temor de Carlos Edmundo de Ory. ${ }^{46}$ Son diecisiete versos-poema o poemas-verso cobijados todos bajo el título común, pero sin título independiente para cada uno y cada uno en página distinta. Son los siguientes:

${ }^{45}$ Laurence BREYSSE, «Gustavo Adolfo Bécquer, huésped de las islas de Manuel Altolaguirre", in Variations autour de la poésie, Hommage à Bernard Sesé, Publications du C.I.I.A, Centre de Recherches Ibériques et Ibéro-Américaines de l'Universite de Paris X-Nanterre, 2001, I, 101-125, 113.

${ }^{46}$ Carlos Edmundo DE ORY, Lee sin temor, Madrid, Editora Nacional, 1976, 197 215. 
«El que camina honor a sus sandalias»

«¿En dónde está ahora quien más me amó en el mundo?»

«¿No te sientes extraño en este mundo?»

«Humanos son los pájaros también»

«La hoz de mi cabeza absoluta»

«El sexo de mi novia es una rosa»

«Hace tiempo que no hago más que mugir»

«Y adiós por fin adiós adiós Erato»

«Oh desenfreno oh freno oh circo oh falo»

«Me acuchillo me tatúo porque sí»»

«La música del ocultismo para orejas»

«Fungió como instrumento de un dictado hechicero»

«Mi mano que ha dormido en el castillo»

«Seda viva mi mugiente mujer»

«Oh cama oh teatro de placer»

«Angel blanco con alas negras negriblanco»

«En la luna no hay rosas ni ratas»

A modo de conclusión, creemos con Daniel Devoto que puede admitirse que el verso existe fuera de la serie: refranes primero, réplicas en el teatro después, versos aislados de su conjunto por puntuación, interrogación o exclamación y/o por espacio. La tendencia de la lengua a formar frases de estructura octosilábica favorece la formación de esas frases-verso. No hay necesidad de evocar un modelo patrón para justificar su existencia. Y hoy, cinco siglos después de la introducción del endecasílabo y casi mil años después de los primeros poemas en castellano, parece juicioso admitir que la lengua ha adquirido la costumbre de utilizar el endecasílabo o el alejandrino sin necesidad de recurrir a un modelo patrón anterior.

Así como los refranes, pueden considerarse versos aislados aquellos que quedan separados respecto a su conjunto por su independencia sintáctica y por la puntuación. Se dan con frecuencia en el Libro de Buen Amor, en la poesía fabulística y en toda la historia de la poesía hasta nuestros días. Muchas veces los poetas inician el poema o lo terminan con un verso que la puntuación aísla de los demás. Cuando esos versos, en general -aunque no siempre- iniciales o finales, se separan del cuerpo 
del conjunto por espacios blancos, entonces su aislamiento resulta evidente. Pero también pueden incluirse aquí las formas esticomíticas y/o esticomíticas-anafóricas que nuestra poesía ha utilizado y utiliza con frecuencia.

El libro A la pintura de Rafael Alberti nos ofrece numerosos casos de versos aislados, sin pertenencia a estrofa o a serie. Son versos independientes los unos de los otros desde el punto de vista de la sintaxis. Su pertenencia a una serie no parece evidente.

Los sonetos de este libro terminan todos con variante de un mismo verso. Puede a partir de ahí matizarse la idea de serie tal como se viene admitiendo. El parentesco de los versos finales de esos sonetos hace pensar en la existencia de series transversales que van enlazando los versos de una composición a otra. Las series en sentido tradicional son series lineales o verticales.

Se distingue el verso aislado del verso solo en que éste se desgaja del cuerpo del conjunto ocupando la página completa, sin título, con el mismo metro o distinto. Es empleo de la poesía moderna.

Lo mismo puede decirse del verso-poema ya anunciado por Bécquer y que se ha manifestado sólo como "ansia" o "deseo" de algún poeta. Salvo algún precedente en Apollinaire, sólo Carlos Edmundo de Ory, salvo error, en sus "Poemas interminables" ofrece un manojo de ellos.

El poeta siempre tiene razón. No cabe discutirle sus intenciones. Si el poeta adopta una manera de expresión, por algo será, aunque no tenga conciencia clara de su motivación. Contentémonos con comprobar. 
